\title{
AGE DIFFERENCES IN PSYCHOACTIVE SUBSTANCE ABUSE IN POPULATION OF THE REPUBLIC OF BELARUS
}

\author{
Vladimir Lelevich,, A, D Hanna Vinitskaya,, A, B, D Yuliya Sarana, 1, B, C Eugenij Tischenko², A \\ ${ }^{1}$ Monitoring Centre for Drugs and Drug Addiction, Grodno State Medical University, Grodno, Belarus \\ 2 Department of Public Health, Grodno State Medical University, Belarus \\ A Study Design, ${ }^{B}$ Data Collection, ${ }^{C}$ Statistical Analysis, ${ }^{D}$ Manuscript Preparation \\ Address for corpespondence: \\ Hanna Vinitskaya, $\mathrm{PhD}$ \\ Monitoring Centre for Drugs and Drug Addiction \\ Grodno State Medical University \\ Gorky Street, 80, 230009 Grodno, Belarus \\ E-mail address: vinhanna3310@gmail.com
}

\begin{abstract}
Ahstract Background. The recent epidemiological studies conducted in Belarus point to a fall in the average age of registered drug abusers and in the age of drug use onset, an increasing proportion of injecting drugs, and addicted persons.

The aim of the study was to evaluate the age differences in the prevalence of psychoactive substance abuse in the Republic of Belarus using the official data of the Ministry of Health.

Material and methods. The data on registered drug abusers, who were recorded in the Narcological Register in health care institutions between 2000 and 2014, were analyzed.

Results. During that period the number of drug abusers under observation increased almost 3 times, and the situation with the spread of psychoactive substances changed towards appearance of synthetic drugs. The spread of particular drugs (opioids, cannabinoides, inhalants, and Spice based designer drugs) was shown to be depended upon the age of registered drug abusers.

Conclusion. The data obtained indicate necessity of the age-related studies on drug abuse prevalence, and might be useful for working up preventive measures to stop the spread of drug addiction.
\end{abstract}

Key WOrds psychoactive substances, drug abusers, Narcological Register, population, Belarus

\section{Introduction}

The prevalence of drugs and drug addiction presents a real problem for many CIS countries including Belarus. A progressive growth of this pathology over the last three decades combined with a number of negative tendencies in drug trafficking are alarming (Koshkina, 2011; Lelevich, Kozlovsky, Vinitskaya, Maksimchuk, 2006; Lelevich, Vinitskaya, Lelevich, 2014; Moskalenko, 2007).

In Belarus, the Narcological Service of the Ministry of Health and the Ministry of Internal Affairs conduct parallel assessments of the spread of psychoactive substances among the population, sharing and coordinating their information (Lelevich et al., 2006). The Narcological Service of Belarus is a network of specialized outpatient 
and inpatient clinics within the public health care system that provides treatment and preventive measures to alcohol and drug abusers. The Narcological Service works with law enforcement agencies, other health authorities and various other government ministries, agencies and non-governmental organisations.

The national health care system maintains a Narcological Register (NR) of non-anonymous patients who are kept under dispensary observation at local narcological and psychoneurological clinics associated with the use of alcohol and other psychoactive substances. The Dispensary Register lists patients diagnosed with psychoactive substance dependence based on the ICD-10 (the 10th revision of the International Classification of Diseases). The casual drug users who have been found with psychoactive substances and their metabolites in their biological liquids but who were not addicted constitute the group on the Prevention Register. The observation period for drug abusers on the Dispensary Register is three years, whereas casual drug users are observed over a one-year period. In case of relapses of drug use the observation period for a patient may be extended indefinitely. At the end of the observation period, a patient may be released from the NR on the following reasons: recovery (or prolonged remission); conviction and imprisonment; change of place of residence; transfer to another medical institution (e.g., psychiatric or other clinic resulting from a change of residence); patient's death; transfer from the Prevention to the Dispensary Register (in cases with developed dependency syndrome). Patients' names and addresses are confidential and are not made public. Other information can be used for professional purposes by other medical institutions, mass media, etc. (Lelevich, Vinitskaya, Lelevich, Maksimchuk, Pekarsky, 2008).

The study was aimed to estimate the spread of psychoactive substance use among different age groups of the population in Belarus using the official data on the psychoactive substance abusers, listed in the NR of the Ministry of Health in 2000-2014.

\section{Material Methods}

The object of the study were statistical data on the patients either diagnosed as drug dependent (ICD-10: F11.2-F.16.2, F18.2- F19.2), or with harmful use of drugs (ICD-10: F11.1-16.1, F18.1-F19.1), who were listed in the Dispensary and Prevention NR of the Ministry of Health of the Republic of Belarus, in 2000-2014. The full database of all non-anonymous drug abusers in Belarus is maintained in the National Monitoring Centre for Drugs and Drug Addiction (NMC) established at the Grodno State Medical University. Today the NMC is the only institution in Belarus responsible for collecting and analyzing information on the prevalence of drug abuse and illicit drug trafficking in the Belarus (Lelevich, Vinitskaya, Lelevich, Tishchenko, Konorazov, 2015). Information on the patients who seek medical aid at narcological clinics or were withdrawn from the NR due to different reasons is included in the statistical records of the Ministry of Health and delivered quarterly to the NMC in form of completed registration cards. Data from the registration cards were entered into a computer database and analyzed statistically. To calculate the indicator, "the prevalence of drug use" (the total amount of drug abusers/addicts registered at the end of the year, per 100,000 population) the information of the National Statistical Committee of the Republic of Belarus on the population of the country has been used.

\section{Results}

According to the NMC estimates 16,975 drug abusers were registered on the Narcological Register (NR) by 31st December 2014, including non-addicted persons and drug addicts (Table 1). Out of those registered drug abusers, 8,711 or $51.3 \%$ were the patients on the Dispensary Register (i.e. their condition was complying with the 
WHO criteria of addiction when they were put on the register). The rest 8,264 casual drug abusers were on the Prevention Register for non-addicted persons who were suspected of using drugs.

In 2014, 3,792 new users of psychoactive substances were added to the NR, 31.6\% of whom had been diagnosed with a psychoactive substance dependency. The same year, 3,143 individuals were released from the register, $19.5 \%$ of those died. The rest drug abusers were released because of recovery, were sentenced, or removed from the register due to other reasons.

We investigated the prevalence of different drug categories among the Belarusian drug abusers of different ages, who were recorded on the NR by the end of 2014 (Table 1).

As of late 2014, the most common psychoactive substance categories were opioids, cannabinoides, solvents and inhalants, "designer drugs", and to a lesser extent - amphetamine-type stimulants, hallucinogens, sedatives and tranquilizers. The share of drug abusers, who preferred the certain drugs, was following: opioids $-63.5 \%$; cannabinoides - 18\%; Spice based designer drugs $-8 \%$; inhalants and solvents $-6.9 \%$; amphetamines $-2.6 \%$; sedatives and tranquilizers $-1.8 \%$; hallucinogens $-0.9 \%$ (Table 1 ).

Table 1. Distribution of drug abusers listed in the Narcological Register of the Ministry of Health of the Republic of Belarus according to age and common psychoactive substances, 2014

\begin{tabular}{|c|c|c|c|c|c|c|c|c|}
\hline \multirow{3}{*}{$\begin{array}{l}\text { Psychoactive substance } \\
\text { category }\end{array}$} & \multicolumn{8}{|c|}{ Age groups } \\
\hline & under & $15-19$ & $20-24$ & $25-29$ & $30-34$ & $35-39$ & 40 years & total \\
\hline & 15 years & years & years & years & years & years & and older & total \\
\hline Opioids & 0 & 51 & 495 & 2,027 & 3,099 & 2,604 & 2,503 & 10,779 \\
\hline Extracted opium & 0 & 41 & 381 & 1,621 & 2,341 & 2,073 & 2,081 & 8,538 \\
\hline Heroin & 0 & 2 & 18 & 60 & 187 & 148 & 103 & 518 \\
\hline Illicit Methadone* & 0 & 2 & 34 & 104 & 231 & 133 & 120 & 606 \\
\hline Cannabinoides & 19 & 543 & 725 & 932 & 517 & 157 & 161 & 3,054 \\
\hline Solvents and inhalants & 79 & 343 & 252 & 315 & 88 & 45 & 49 & 1,171 \\
\hline Amphetamine-type stimulants & 2 & 31 & 85 & 131 & 99 & 42 & 62 & 452 \\
\hline Hallucinogens & 10 & 53 & 35 & 27 & 10 & 10 & 12 & 157 \\
\hline Sedatives and tranquillizers & 1 & 8 & 20 & 32 & 47 & 53 & 151 & 312 \\
\hline Designer drugs ${ }^{* *}$ & 40 & 723 & 337 & 111 & 94 & 30 & 30 & 1,364 \\
\hline Total for Belarus & 133 & 1,408 & 1,866 & 3,610 & 4,003 & 2,962 & 2,993 & 16,975 \\
\hline
\end{tabular}

Note: * - including the cases of combined use of methadone and other opioids (opium, heroin, etc); ** including combined use of Spice based designer drugs, injective psychostimulants and other psychoactive substances.

We analyzed the age distribution of men and women, as well as addicted and non-addicted persons, recorded in the Belarusian narcological clinics by the end of 2014 (Figures 1 and 2).

Males constituted the majority of the registered drug abusers in Belarus. By the end 2014, 14,466 men (85.2\%) and 2,509 women (14.8\%) were registered as psychoactive substance users in Belarusian narcological institutions. The "men to women" ratio was equal 5.7 to 1 . The mean age of the male drug abusers, listed in the NR in 2014, was 34.78 .8 years (mean \pm standard deviation), and their ages ranged from 7 to 60 . However, the ages of women ranged from 11 to 58 , and their mean age was comparatively lower (32.4 \pm 8.5 ) (Figure 1).

Males predominated in all age groups of the registered drug abusers. However, the older group of drug abusers was analyzed; there were more women abusing drugs. In 2014 , women comprised $12,4 \%$ of the drug 
abusers aged under 20. However, among the patients aged 45 and above, the proportion of women was $15.5 \%$ (Figure 1).

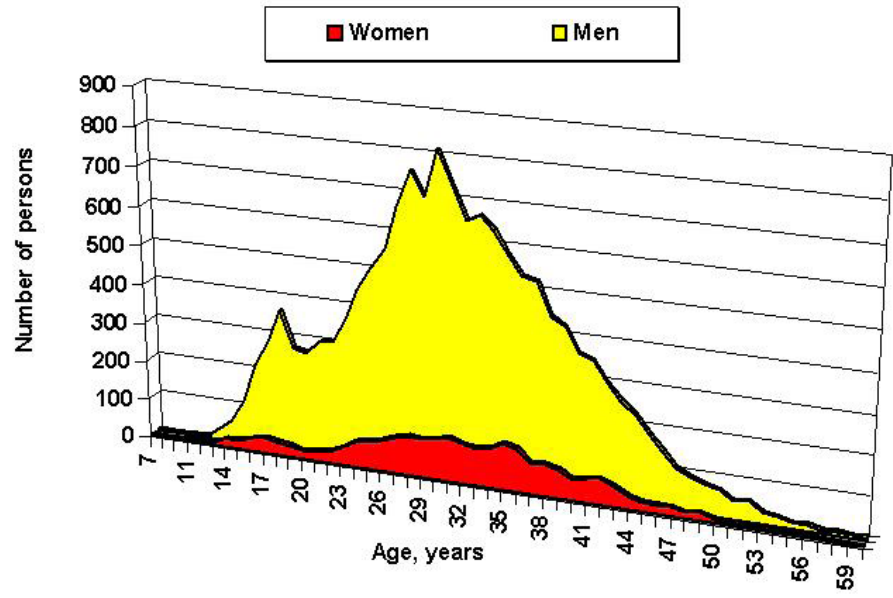

Figure 1. Age distribution of men and women listed in the Narcological Register of the Ministry of Health of the Republic of Belarus, 2014

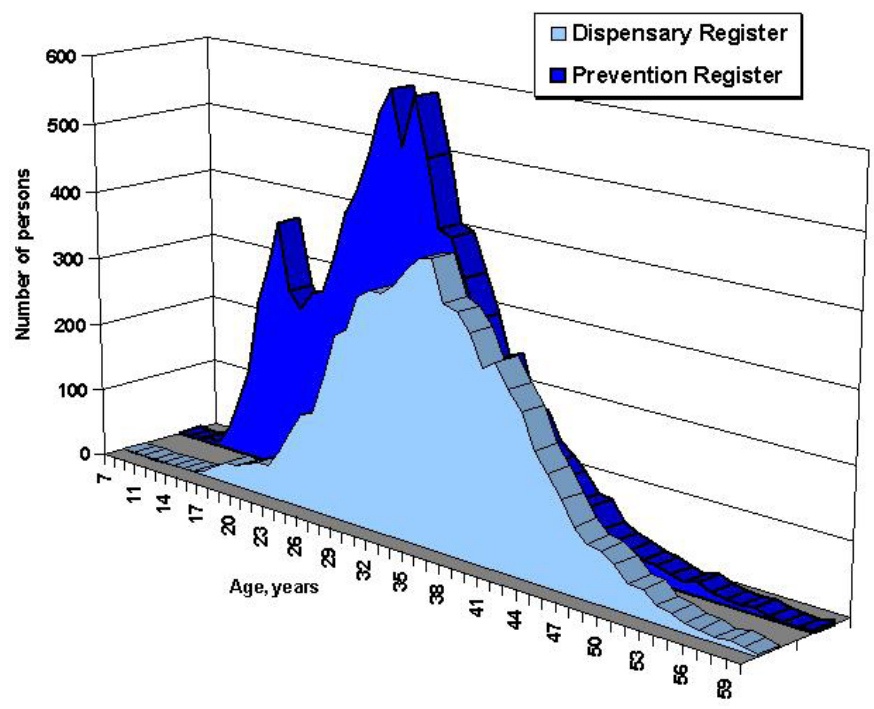

Figure 2. Age distribution of drug abusers, who were recorded on the Prevention and Dispensary Narcological Registers of the Ministry of Health of the Republic of Belarus, 2014 
In 2014 the age of the drug abusers, who were under medical surveillance in Belarus, ranged from 7 year-old children abusing solvents to 60 year-old opioid injectors (Table 1; Figure 1). About $80 \%$ of all illicit drug abusers were aged 25 and above, and the mean age of these persons was $34.1 \pm 9.1$ years.

In 2014133 children aged 7 to 14 were under medical surveillance in narcological institutions because of use of different psychoactive substances. Among them there were 101 boys and 32 girls. In 2014,1408 or $8.3 \%$ of drug abusers were aged 15 to 19 , and $10 \%$ of them were girls (Table 1; Figure 1). Only 102 of these young people were addicted, and placed on the Dispensary NR according to the clinical criteria of ICD-10 (Figure 2).

According to the NMC estimates, $11 \%$ of all registered drug abusers were aged 20 to 24 , whereas the older drug patients constituted almost $80 \%$ of all persons registered on the NR in Belarus. Other age groups constituted, subsequently, $21.3 \%$ for drug abusers aged 25 to $29 ; 23.6 \%$ for those aged 30 to $34,35.1 \%$ for those aged 35 years and above (Table 1). It was shown that the ratio of addicted persons was higher among the older drug abusers. In 2014 the share of addicted persons among registered drug abusers constituted even $71.2 \%$ among those aged 40 years and more, whereas only $16.6 \%$ of the young addicts aged 20 to 24 were registered on the Dispensary Register (Figure 2).

\section{Discussion}

According to official statistical data of the Ministry of Health of Belarus at the end of 2014, narcological and psychoneurological dispensaries had registered 188,260 alcoholics and alcoholic psychosis patients, or 1,985.7 per 100,000 of the population (1,426.0 per 100,000 in 2000 (Ministry of Health of the Republic of Belarus 2014). Whereas the number of the persons abusing other psychoactive substances constituted 16,975 , including casual users and patients with dependency syndrome (Table 1). A comparison of statistical data on alcoholics and drug addicts shows that alcoholism is much more widespread among the population than drug addiction. However, two factors must be taken into account here: first, there is more latent drug addiction than latent alcoholism and, second, the social risks associated with drug addiction are greater than those associated with alcoholism (Koshkina, 2003).

Over the last 14 years the prevalence of non-prescription use of psychoactive substances has become a pressing issue in Belarus. According to the NMC estimates, the number of drug abusers under observation increased almost 3 times between 2000 and 2014: At the end of 2000 it stood at 6,310 persons throughout Belarus. In 2014 the indicator of "the prevalence of drug use" was 179 drug abusers per 100,000 of the country population, whereas in 2000 , it was 67.4 per 100,000 of the population.

It has been shown before that drug users living in different regions of Belarus, differed on the number of socio-epidemiological parameters, including sex ratio, age characteristics and preferences of different types of psychoactive substances (Lelevich et al., 2014). In 2014 the city of Minsk and the Gomel region reported the majority of new cases of drug use and had the highest cumulative number of registered drug users per 100,000 of the population (306.3 in Minsk, and 190 in the Gomel region). The Mogilev region had the smallest number of registered drug users per 100,000 (98 in 2014).

National epidemiological studies point to a fall in the average age of registered drug abusers and in the age at which drug use begins, an increasing proportion of hard drugs, and addicted persons (Lelevich et al., 2008, Lelevich et al., 2014). According to the official statistic of the Narcological Service at the end of 2014, 8,711 persons (or $51.3 \%$ ) were recorded on the Dispensary NR for the patients with diagnosed dependency syndrome. The rest 8,264 casual drug abusers were on the Prevention NR. 
Overall, statistics have shown that illicit drug abuse rises with age until it peaks at ages when people begin to inject drugs (Table 1). In 2014 the age of the drug abusers, who were under medical surveillance in Belarus, ranged from 7 years children abusing solvents to 60 years opioid injectors (Table 1; Figure 1).

Epidemiological studies carried out in different countries show that the drug use is considered as a "male phenomenon "(Becker, Hu, 2008, Degenhardt et al., 2008). Animal research and human studies have revealed that males and females may differ in their biological responses to drugs. From the neurobiological point of view, men are more likely than women to abuse drugs that might be explained by hormonally-mediated differences in the neurochemical reactions in response to the drug (Stevens, Andrade, Ruiz, 2009).

Among Belarusian drug patients, men constituted the majority of the registered drug abusers, who were under medical surveillance in 2014. At the end of 2014, male drug abusers comprised $85.2 \%$ and women $14.8 \%$. Out data are consistent with the latest data of the UN Office on Drugs and Crime (UNODC). According to the World Drug Report for 2015, women make up one-fifth of all drug users in treatment, whereas their real number may be even one-third (UN World Drug Report 2015). According to the previous observations in Belarus women usually start to use psychoactive substances in older ages compared to men (Razvodovsky, Vinitskaya, Lelevich, 2010; Lelevich et al., 2015). The mean age of women, who were registered on the NR in 2014, was slightly lower than the mean age of men (32.4 \pm 8.5 years against $34.7 \pm 8.8$ ). The youngest reported age of a female substance abuser was 11 , whereas for the boy this age was 7.

It was found that men predominated in all age groups of the registered drug abusers in Belarus. However, the older group of them was analyzed; there were more women who abuse drugs. In 2014, women comprised $12,4 \%$ of the drug abusers under the age of 20 . However, among the patients aged 45 and older, the proportion of women was $15.5 \%$ (Figure 1).

The structure of the drug market in Belarus reflects changes that have taken place in the structure of global trafficking routes. Belarus finds itself now at the intersection of plant drug routes running in parallel from Southeast Asia and Central Asia to destinations in Western and Northern Europe, while some synthetic drugs and psychotropic substances are trafficked eastward. Due to the "transparency" of its external borders, especially the border with the Russian Federation, the territory of Belarus continues to play a significant role in drug trafficking. At the same time, cases of cultivating drug containing plants with the goal of producing drugs have been registered in country (Lelevich et al., 2008).

Epidemiological studies carried out it Belarus point to the following main categories of psychoactive substances that are spread among registered drug abusers.

Opioids category of drugs includes homemade opium (extracted or acetylated opium made from poppy straw or seeds of the Papaver plants), heroin, and street methadone. There are also cases of misuse of pharmaceutical opioids, such as morphine, codeine, and tramadol.

Cannabinoides group include marijuana (herb) and hashish (resin), and also Spice based smoking mixtures, containing synthetic cannabinoides, (JWH-type, AB-PINACA, etc.).

Amphetamine-type stimulants include amphetamine, methamphetamine, and 'Ecstasy'-type substances (e.g. MDA, MDMA), Other cases include use of ephedron, pyrovalerone, mephedrone, and 'Nasvai' (the mixture with a slightly hallucinogenic properties composed of tobacco dust, glue, lime, water or vegetable oil, rolled into small balls. "Nasvai" is mainly used by teenagers). 
Sedatives and tranquilizers include barbiturates, benzodiazepines and other sedatives. There are the cases of misuse of prescribed drugs Xanax, Zopiclone, Afobazol, Somnol, Sonnat. As well as misuse of "Corvalol" and "Valocordin", which are the prescribed medicines, containing low doses of barbiturates.

Hallucinogens category include misuse of some medications such as taren, dicyclomine, cyclodol, dymedrol, and per oral use of atropine-containing seeds and extracts from plants Racinus communis L., Datura stramonium, Hyoscyanius niger $L$.

Designer drugs category includes all recorded cases of the use of smoking mixtures, containing synthetic cannabinoides, as well as injecting of some psychostimulants.

According to the UNODC estimates, opioid drugs are some of the most widely used in European and Asian countries (UN World Drug Report, 2015). Over the last three decades, opioids were the most common drugs in Belarus (Vinitskaya, Lelevich, Razvodovsky, 2012). More than $80 \%$ of users of opium-based drugs, who were placed on the NR showed a preference for intravenous injection of extracted or acetylated opium made up from poppy straw or seeds of edible grades of Papaver somniferum $L$. These homemade opioids were used extensively among drug addicts in nearly all regions of the country, as poppies and precursors for making a narcotic extract are readily available (Lelevich et al., 2008).

As of late $2014,10,779$ opioid users were recorded in the Narcological Register, or $63.5 \%$ of all registered cases (Table 1). $72 \%$ of these cases were listed in the Dispensary NR (ICD-10, F 11.2) and the rest were listed in the Prevention NR with a diagnosis of harmful use of opioids (ICD-10, F 11.1). The overwhelming majority of opioid users $(95.3 \%)$ were intravenous users.

In 2014, almost half of all recorded drug abusers in Belarus (50.3 \%) injected extracted opium, as the most available and cheep drug ("kompot"). Unlike the EU countries, heroin users comprised only $3.1 \%$ of all reported drug abusers in Belarus. According to the European Monitoring Centre on Drugs and Drug Addiction, heroin is the most popular opioid in the EU countries, whereas the use of home-made poppy prevails mainly in the Eastern European countries (EMCDDA European Drug Report 2016). Besides, street methadone was used by $3.6 \%$ of all registered drug abusers in Belarus (Table 1).

Cannabinoides and inhalant were on the second and third positions in Belarus, and abusing them persons constituted, respectively, $18 \%$ and $6.9 \%$ of all registered drug abusers in 2014 . The use of some amphetamine-type stimulants is spread in Belarus to a lesser extent, although these drugs predominate in Western Europe, as the common drugs for injecting (EMCDDA European Drug Report 2016). The rest registered drug abusers consumed sedatives and tranquillizers (barbiturates, benzodiazepines) (1.8\%) and hallucinogens (1\%) (Table 1).

In addition to the above-mentioned psychoactive substances, we analyzed the cases of abuse of so-called "designer drugs", compounds with modified chemical formula. According to the Belarusian experts, the most common substances found in these smoking mixtures were JWH-type synthetic cannabinoides (more often JWH018), AB-PINACA, AB-PINACA-F, AB-PINAC, AB-PINACA CHM, psychostimulants like MDPV, alpha-PVP, and other psychotropic substances (4-MeO-PCP, MBA(N)-018, QCBH-DZ-F, QCBL). There were also cases of injecting use of Psychostimulators, such as MDPV and alpha-PVP.

In Belarus the sudden growth in the number of recorded patients poisoned with Spice based designer drugs is observed since 2013. If in 2010-2012 the number of identified users of these mixtures had ranged from 4 to 7 persons, by the end of 2013 , there were 334 officially registered users of designer drugs. The most sudden growth in the number of recorded poisonings with these substances was observed in 2014. As of December 31, 2014, drug 
treatment facilities in Belarus recorded 1364 persons, abusing various substances with modified formula (Table 1). Of those persons, $43 \%$ were residents of the capital city of Minsk.

The age distribution of the registered substance abusers was highly dependent on their gender and narcological diagnosis (Figures 1 and 2).

In 2014 the youngest drug abusers treated in Belarusian narcological clinics were aged from 7 to 14 . They constituted only $0.8 \%$ of all registered drug abusers. Only 3 of these children were diagnosed as dependent from solvents and inhalants, according to the clinical criteria of the ICD-10. The rest of the children were placed on the Prevention Narcological Register (Table 1; Figure 2). The vast majority of these children preferred inhalants (volatile solvents, glues) (59.4\%) and Spice type smoking mixtures (30\%). Other registered young abusers consumed herbal cannabinoides (14.3\%) and amphetamine stimulants (ecstasy) (1.5\%). Besides, 10 teenagers were hospitalized in 2014 as the result of poisoning with atropine-containing plants, mainly hog bean (Hyoscyamus L. niger), jimsonweed (Datura stramonium L.), and castor bean (Ricinus communis L.), and 1 person was registered after poisoning with barbiturates. In 2014 there were no registered cases of injecting drug use among young people aged under 15 (Table 1).

In 2007 the ESPAD-based regional study on the prevalence of drug use among students aged 15-16 was conducted in the Brest region. The survey demonstrated that $10.5 \%$ of boys and $3.5 \%$ of girls reported use of psychoactive substances at least once in their life. Among psychoactive substances used the most common were marijuana (6.8\% of all respondents), ecstasy (1.3\%), LSD (0.9\%) and hallucinogenic mushrooms $(0.4 \%) .5 .3 \%$ of respondents admitted to the use of inhalants during their life and $1.1 \%$ said that they had used tranquilizers without a doctor's prescription (Avsievich, Danilova, Krasko, Golovach, Seredich, 2008). Therefore, our data on the registered teenagers treated in narcological clinics are consistent with the data of sociological surveys performed among Belarusian students.

In 2014,1408 or $8.3 \%$ of drug abusers were aged 15 to 19 , and $10 \%$ of them were girls (Table 1, Figure 1). The vast majority of these young abusers were placed on the Prevention NR mainly due to the information of law enforcement and medical agencies, or educational institutions. Only 102 of them young people were addicted, and placed on the Dispensary NR according to the clinical criteria of ICD-10 (Figure 2). Unlike the youngest group the substance abusers of this age category preferred herbal cannabinoides (38.6\%) and Spice based designer drugs $(51.3 \%)$ compared to the youngest drug abusers. About a quarter of the $15-19$ aged patients $(24.4 \%)$ misused solvents and inhalants that was less then among the youngest group of drug abusers. On the other hand, there were 51 drug abusers aged from 17 to 19 who injected opioids, mainly extracted opium (Table 1). This founding indirectly points to the fact that the young people of these ages begin to experiment with so-called soft drugs, and then gradually move to "hard' injecting opioids. These observations are consistent with our previous studies carried out in 2007 (Razvodovsky et al., 2010).

Our data show that in Belarus the spread of particular drugs among registered drug abusers is highly dependent on their ages. For example among the individuals aged 20 to 24 opioid abusers comprised $26.5 \%$. Among drug abusers older than 25 years the proportion of people who use opioids ranged from $56 \%$ among the drug patients aged $25-29$ to $84 \%$ among the patients aged 40 years and above (Table 1). The preference for opiate drugs has led to the faster development of the dependency syndrome in the older drug abusers. According to our data, the share of addicted persons constituted even $71.2 \%$ among those aged 40 years and above, whereas only $16.6 \%$ of the young addicts aged 20 to 24 were registered on the Dispensary NR (Figure 2). 
Opioid abusers of different ages show preference to certain types of opioids. Although the vast majority of Belarusian opioid abusers preferred extracted opium made up of poppy straw and seeds, injecting use of heroin and street methadone was noted mainly in the groups of patients aged 20 to 39 (Table 1).

At the same time, the spread of typically recreational drugs like marijuana and Spice based smoking mixtures rather predominated among the younger drug abusers. As for the end of 2014, the share of the cannabinoides abusers varied from $39 \%$ among the $20-24$ aged persons to $5.4 \%$ among to those aged 40 years and above (Table 1). Low recreational doses of spice compounds or bath salts produce the expected desirable effects, but high doses or chronic exposure can lead to dangerous medical consequences including psychosis, violent behaviors, tachycardia, hyperthermia, and even death (Baumann et al., 2014).

According to statistical data of the Ministry of Health of Belarus for 2014 year, amphetamines and different "designer drugs" were mainly distributed among men and the drug abusers in the age groups up to 25 years (Table 1). For example, the proportion of underage persons abusing "designer drugs" (under 18) constituted even $32 \%$. In 2014 the youngest "spice" smoker was 9 years old at the time of his registration in the NR. Cumulatively more then $80 \%$ persons, who were poisoned with the Spice based substances in the reporting year were aged less than 25 years. The older users of designer drugs were polydrug users and combined abuse of smoking mixtures with injecting of opioids, or amphetamine-type stimulants.

In addition, the misuse of legal prescription drugs was also more characteristic for older patients treated in Belarusian narcological clinics. In 2014 more than 58\% of the persons listed in the NR because of misuse of barbiturates and benzodiazepines were older than 40 years (Table 1).

\section{Conclusions}

1. Analysis of the official data of the Ministry of Health of the Republic of Belarus can give insight of the real situation on the prevalence of psychoactive substance use in Belarus.

2. Over the period from 2000 to 2014 the number of drug abusers recorded in the Narcological Register increased almost 3 times, and the situation with the spread of psychoactive substances is changing towards appearance of synthetic drugs.

3. In 2014 among the registered drug patients in Belarusian narcological clinics the most common drugs were extracted opium, herbal and synthetic cannabinoides, solvents and inhalants.

4. In Belarus, the abuse of psychoactive substances increasingly spread among men compared to women. At the end of 2014 men constituted $85.2 \%$ of all drug abusers registered on the NR.

5. In 2014, the age range of the drug patients registered on the NR, varied from 7 to 60 years. However, the vast majority of recorded drug users in Belarus were aged 25 and above, and the mean age of these persons was $34.1 \pm 9.1$ years.

6. It was shown, that drug abusers of different ages preferred certain types of psychoactive substances. Among the drug patients aged fewer than 20 the most common drugs were cannabinoides, inhalants, and Spice type smoking mixtures. Injecting opioids were mainly spread among drug abusers older than 20 years, and the share of these persons increased with the age.

7. The data obtained indicate necessity of the age-related studies on drug abuse prevalence, and might be useful for working up preventive measures to combat the spread of drug addiction 


\section{References}

Avsievich, N., Danilova, S., Krasko, N., Golovach, T., Seredich, N. (2008). Outcomes of school study using the ESPAD methodology conducted in 2007 among the students of Brest Oblast. Brest.

Baumann, M.H., Solis, E., Watterson, L.R., Marusich, J.A., Fantegrossi, W.E., Wiley, J.L. (2014). Baths Salts, Spice, and Related Designer Drugs: The Science behind the Headlines. The Journal of Neuroscience, 34 (46), 15150-15158. DOI: 10.1523/ JNEUROSCI.3223-14.2014.

Becker, J.B., Hu, M. (2008). Sex Differences in Drug Abuse Frontiers in Neuroendocrinology, 29 (1), 36-47. DOI:10.1016/j. yfrne.2007.07.003.

Degenhardt, L., Chiu, W.-T., Sampson, N., Kessler, R.C., Anthony, J.C., Angermeyer, M., ..., Wells, E.J. (2008). Toward a Global View of Alcohol, Tobacco, Cannabis, and Cocaine Use: Findings from the WHO World Mental Health Surveys. PLoS Med, 5 (7), e141. DOI:10.1371/journal.pmed.0050141.

European Monitoring Centre for Drugs and Drug Addiction. (2016). European Drug Report 2016. Trends and Developments. Luxembourg: Publication Office of the European Union.

Koshkina, E.A. (2003). Trends in the prevalence of psychoactive substance use in the Russian Federation. Bulletin of Narcotics, $25(1-2), 121-130$.

Koshkina, E.A. (2011). Medical and social consequences of substance abuse for the health of the nation. Journal of Addiction Problems, 5, 27-30.

Lelevich, V.V., Kozlovsky, A.V., Vinitskaya, H., Maksimchuk, V.P. (2006). Drug use and illicit drug trafficking in Belarus. Minsk: Altiora.

Lelevich, V., Vinitskaya, H., Lelevich, S. (2014). Ocena rozpowszechnienia używania substancji psychoaktywnych wśród ludności na Białorusi. Probl Hig Epidemiol, 95 (2), 407-411.

Lelevich, V.V., Vinitskaya, H., Lelevich, S.V., Maksimchuk, V.P., Pekarsky, O.A. (2008). Report on drug abuse and illegal drug trafficking in Belarus/Programme of Assistance for the Prevention of Drug Abuse and Drug Trafficking in Belarus, Ukraine and Moldova (BUMAD). Minsk: Belsens.

Lelevich, V.V., Vinitskaya, A.G., Lelevich, S.V., Tishchenko, Ye.M., Konorazov, I.I. (2015). Gender and age aspects of the prevalence of drug abuse in the Republic of Belarus. Vestnik of the Smolensk State Medical Academy, 14 (2), 7-13.

Ministry of Health of the Republic of Belarus State Institution «Republican Scientific and Practical Center for Medical Technologies, Informatization, Administration and Management of Health». (2015). Public health in the Republic of Belarus An official statistics collection, 2014. Minsk, 282. Retrieved from: http:// http://www.med.by/content/stat/stat2015/2014_1.pdf.

Moskalenko, V.D. (2007). Social consequences of alcoholism and drug addiction. Narcology, 3, 25-29.

Razvodovsky, Y.E., Vinitskaya, A.G., Lelevich, V.V. (2010). Gender aspects of the prevalence of drug abuse in the Republic of Belarus. Narcology, 11, 22-27.

Stevens, S.J., Andrade, R.A.C., Ruiz, B.S. (2009). Women and substance abuse: Gender, age, and cultural considerations. Journal of Ethnicity in Substance Abuse, 8 (3), 341-358. DOI: 10.1080/15332640903110542.

Vinitskaya, A.G., Lelevich, V.V., Razvodovsky, Y.E. (2012). The prevalence of opiate addiction in the Republic of Belarus. Meditsinskie novosti, 1, 41-44.

United Nations Office on Drugs and Crime. (2015). World Drug Report 2015. Retrieved from: https://www.unodc.org/documents/ wdr2015/World_Drug_Report_2015.pdf.

Cite this article aS: Lelevich, V., Vinitskaya, H., Sarana, Y., Tischenko, E. (2016). Age Differences in Psychoactive Substance Abuse in Population of the Republic of Belarus. Central European Journal of Sport Sciences and Medicine, 15 (3), 85-94. DOI: 10.18276/ cej.2016.3-9. 